\title{
Endothelin-1 and interleukin-8 in high altitude pulmonary oedema
}

\author{
Y. Droma, T. Hayano, Y. Takabayashi, T. Koizumi, K. Kubo, \\ T. Kobayashi, M. Sekiguchi
}

Endothelin-1 and interleukin-8 in high altitude pulmonary oedema. Y. Droma, T. Hayano, Y. Takabayashi, T. Koizumi, K. Kubo, T. Kobayashi, M. Sekiguchi. (CERS Journals Ltd 1996.

ABSTRACT: We present a case of high altitude pulmonary oedema (HAPE) with pulmonary hypertension and polymorphoneuclear leucocyte (PMN) accumulation in bronchoalveolar lavage fluid (BALF), which occurred in a 21 year old man.

Plasma endothelin-1 (ET-1) and interleukin-8 (IL-8) concentration in BALF were elevated on admission, and returned to normal level at recovery, when the pulmonary artery pressure and the PMN counts in BALF were normal. In addition, E-selectin and intercellular adhesion molecule-1 (ICAM-1) in BALF were also slightly increased on admission.

These findings suggest that endothelin-1 is a vasoconstrictor which contributes to the pulmonary hypertension in high altitude pulmonary oedema, and that some of the inflammatory mediators play an important role in chemotaxis and accumulation of polymorphonuclear leucocytes in the development of high altitude pulmonary oedema.

Eur Respir J., 1996, 9, 1947-1949.
First Department of Internal Medicine, Shinshu University School of Medicine, Asahi, Matsumoto, Japan.

Correspondence: T. Koizumi, First Department of Internal Medicine, Shinshu University School of Medicine, 3-1-1 Asahi, Matsumoto, 390 Japan

Keywords: Adhesion molecules bronchoalveolar lavage fluid cytokine pulmonary hypertension

Received: October 121995 Accepted after revision March 71996
High altitude pulmonary oedema (HAPE) is a severe type of acute mountain sickness. It is a serious, sometimes fatal illness related to rapid exposure to altitude. Although the pathophysiological mechanism of HAPE remains unclear, it has long been suggested that pulmonary vasoconstriction and increased pulmonary vascular permeability are important contributory factors $[1$, 2]. Recent studies have suggested that endothelin is related to pulmonary vasoconstriction [3-5], and that the increased pulmonary vascular permeability is probably caused by inflammatory mediators [6-10]. However, no studies have been conducted on the role of endothelin and cytokines in patients with HAPE. We report a case of HAPE, documenting the possible role of endothelin1 (ET-1), and polymorphoneuclear leucocyte (PMN) chemotactic mediators, such as interleukin-8 (IL-8).

\section{Case report}

A Japanese male university student, aged 21 yrs, who was healthy before climbing, arrived at the foot of the Japan Alps at 1,000 m above sea level. The next morning, he started climbing to a snowy valley about 2,000 $\mathrm{m}$ above sea level and still felt well. On the third day, whilst climbing to Mt Yari $(3,180 \mathrm{~m})$, he developed general fatigue, followed by headache, cough, sputum, poor appetite and fever $\left(38^{\circ} \mathrm{C}\right)$. After staying all day to rest at $3,000 \mathrm{~m}$, his condition progressively deteriorated. On the fifth day, he was lethargic, comatose, cyanotic, and had a cough with foamy sputum. He was rescued, transported by helicopter, and admitted to our Shinshu University Hospital (660 m).
On admission, he had cyanosis and was unconscious. His temperature was $38^{\circ} \mathrm{C}$, pulse rate 140 beats $\cdot \mathrm{min}^{-1}$, respiration rate 26 breaths $\cdot \mathrm{min}^{-1}$, and his blood pressure $140 / 90 \mathrm{mmHg}$. Coarse crackles were audible over both sides of the lung. He showed decerebrate rigidity. An examination of the ocular fundi showed papilloedema and multiple flame-shaped and blot haemorrhages in both fundi. A chest roentgenogram revealed patchy infiltrates in both lung fields, with a cardiothoracic ratio (CTR) of 59\%. Computerized tomography (CT) showed a severe brain oedema. White blood cell count (WBC) on admission was $1.7 \times 10^{9}$ cells $\cdot \mathrm{L}^{-1}$ (PMNs $\left.87 \%\right)$. Arterial blood gas analysis (room air) revealed an arterial oxygen tension $\left(\mathrm{Pa}, \mathrm{O}_{2}\right)$ of $4.0 \mathrm{kPa}$ (30 torr), an arterial carbon dioxide tension $\left(\mathrm{Pa}_{\mathrm{a}} \mathrm{CO}_{2}\right) 3.8 \mathrm{kPa}$ (30 torr), and $\mathrm{pH}$ of 7.50 .

The pulmonary haemodynamics and endothelin-1 (ET-1) concentrations in systemic and pulmonary circulation on admission and recovery are shown in table 1 . Right heart catheterization on admission revealed pulmonary hypertension (mean pressure $34 \mathrm{mmHg}$ ) combined with normal pulmonary artery wedge pressure and cardiac output. The blood samples of ET-1 were drawn from the brachial and pulmonary artery. ET-1 was measured by radio-immunoassay (RIA), as described previously [11]. Plasma ET-1 levels in the systemic and pulmonary artery were elevated on admission. The concentration of ET-1 in the systemic circulation was higher than that in the pulmonary circulation on admission. The ET-1 level returned to normal within 4 days of hospitalization, concomitant with the decrease in pulmonary artery pressure.

The data obtained from the bronchoalveolar lavage fluid (BALF) are summarized in table 2. On admission 
Table 1. - Pulmonary haemodynamics and endothelin concentrations breathing room air

\begin{tabular}{lcc}
\hline & On admission & $\begin{array}{c}\text { Recovery } \\
\text { Day 4 }\end{array}$ \\
\hline $\bar{P}$ pa mmHg & 34 & 16 \\
$P \mathrm{cw} \mathrm{mmHg}$ & 11 & 7 \\
$\mathrm{CI} \mathrm{L} \cdot \mathrm{min}^{-1} \cdot \mathrm{m}^{-2}$ & 5.0 & 3.7 \\
$\mathrm{PVRI} \mathrm{mmHg} \cdot \mathrm{L}^{-1} \cdot \mathrm{min} \cdot \mathrm{m}^{-2}$ & 4.6 & 2.4 \\
Endothelin-1 $\mathrm{pg} \cdot \mathrm{mL}^{-1}$ & & \\
$\quad$ Systemic & 7.1 & 4.0 \\
Pulmonary & 4.6 & 3.8 \\
\hline
\end{tabular}

$\bar{P}$ pa: mean pulmonary artery pressure; $\bar{P} \mathrm{cw}$ : mean capillary wedge pressure; CI: cardiac index; PVRI: pulmonary vascular resistance index.

Table 2. - Characteristics of the bronchoalveolar lavage fluid (BALF)

\begin{tabular}{lcc}
\hline & On admission & Recovery \\
\hline BALF Recovery \% & 30 & 60 \\
Albumin mg $\cdot \mathrm{dL}^{-1}$ & 467 & 31 \\
Total cell count $\times 10^{5} \cdot \mathrm{mL}^{-1}$ & 5.53 & 1.13 \\
Macrophages \% & 41.5 & 97.5 \\
PMNs \% & 52.5 & 1.5 \\
Lymphocytes \% & 6.0 & 1.0 \\
IL-8 pg $\mathrm{mL}-1$ & 3620 & $<10$ \\
E-selectin ng $\cdot \mathrm{mL}^{-1}$ & 2.5 & $<1.2$ \\
P-selectin $\mathrm{ng} \cdot \mathrm{mL}^{-1}$ & $<10$ & $<10$ \\
ICAM-1 ng. $\mathrm{mL}^{-1}$ & 396 & 207 \\
VCAM-1 ng $\cdot \mathrm{mL}^{-1}$ & $<56$ & $<56$ \\
\hline
\end{tabular}

PMNs: polymorphonuclear leucocytes; ICAM-1: intercellular adhesion molecule-1; VCAM-1: vascular cell adhesion molecule-1; IL-8: interleukin-8.

the bronchoalveolar lavage (BAL) was performed by injection and withdrawal of $50 \mathrm{~mL}$ of normal saline, and was repeated three-times during recovery. The percentage of PMNs and albumin concentration in BALF were markedly elevated on admission. Interleukin-8 (IL-8) was measured with a sandwich enzyme-linked immunosorbent assay (ELISA). Four soluble types of adhesion molecules were also measured, intercellular adhesion molecule-1 (ICAM-1), vascular cell adhesion molecule1 (VCAM-1), E- and P-selectin in the BALF using ELISA methods. The concentration of IL-8 was considerably increased on admission as compared to recovery.

The patient was treated with oxygen and adequate fluid infusion. His condition gradually improved, and the infiltration on the chest roentgenogram had disappeared within 1 week.

\section{Discussion}

In this patient with HAPE, we found that pulmonary hypertension was associated with an increased plasma level of ET-1, and that PMN accumulation was also associated with an increased level of IL- 8 and of some of the adhesion molecules in the airspace.

It has been shown that hypoxic pulmonary vasoconstriction is the main contributing factor in the pulmonary hypertension of HAPE $[1,2]$. However, other unknown factors may be involved in the development of pulmonary hypertension in HAPE, because an adequate oxygen supply does not completely reverse the pulmonary hypertension. ET-1 has been shown to be a potent pulmonary vasoconstrictor [5]. Acute pulmonary alveolar hypoxia increases lung and plasma ET-1 levels, which were parallel to the severity of hypoxia in conscious unrestrained rats [12] and human [4]. In the present case, the plasma ET-1 levels in both systemic and pulmonary arteries on admission were higher than at recovery, suggesting that ET-1 could be partially responsible for the pulmonary hypertension. In healthy volunteers, GoERre et al. [4] reported that venous and arterial levels of ET-1 were similar at low altitude, but arterial ET-1 was lower than venous ET-1 at high altitude $(4,559 \mathrm{~m})$. Contrary to their study, the systemic level was higher than that of the pulmonary level on admission in the present case. It may reflect the differences in clearance and/or production of ET-1 in the lung between healthy subjects and subjects with HAPE.

Our patient presented an elevated level of IL- 8 with PMN accumulation in the airspace. It was reported that the BALF obtained from the subjects with HAPE at 4,400 $\mathrm{m}$ on Mount McKinley had markedly increased protein and PMN percentage, with elevated levels of leukotriene $\mathrm{B}_{4}\left(\mathrm{LTB}_{4}\right)$ and complement factor $5 \mathrm{a}(\mathrm{C} 5 \mathrm{a})$ in the airspace [13]. These studies suggested that inflammation contributed to the pathogenesis of HAPE. IL- 8 has been characterized as a PMN chemoattractant and a proinflammatory mediator [8, 9]. MiLLER et al. [8] reported that elevated levels of IL- 8 and PMN counts were present in the airspace of patients with adult respiratory distress syndrome (ARDS), and that these findings were associated with the increased mortality. DonNELly et al. [9] demonstrated a close association between IL-8 in BALF from ARDS at-risk patients on initial hospital admission and their subsequent ARDS progression. Interestingly, even though the present case showed a higher level of IL-8 $\left(3,620 \mathrm{pg} \cdot \mathrm{mL}^{-1}\right)$ in BALF than that in the ARDS described by another report $(1,024 \pm 250$ $\left.\mathrm{pg} \cdot \mathrm{mL}^{-1}\right)$ [8], the patient recovered within a week. Therefore, the pathophysiological role of IL-8 in HAPE may be different from ARDS, even though the elevation of IL-8 and recruitment of PMNs into the airspaces were similar in both diseases. To our knowledge, this is the first report to measure IL-8 in BALF of HAPE. We need more evidence to support and/or elucidate our findings concerning the role of IL-8 in HAPE.

Our patient also showed an increased level of E-selectin and ICAM-1 in BALF. ELDRIGE et al. [14] found an elevated plasma level of E-selectin after climbing at high altitude, but no significant differences were observed between non-ill climbers and those with HAPE. These studies and our data suggest that an inflammatory process via the adhesion molecules is involved in the adaptation to high altitude. However, the role of adhesion molecules in the pathogenesis of HAPE remains uncertain.

In summary, we have found, in a case of high altitude pulmonary oedema, that pulmonary hypertension and intrapulmonary polymorphonuclear leucocyte accumulation were associated with an increase in plasma level of endothelin-1 and interleukin-8 in bronchoalveolar lavage fluid, respectively. We speculate that endothelin-1 and interleukin- 8 are important contributory factors in the pathogenesis of high altitude pulmonary oedema. 


\section{References}

1. Reeves JT, Schoene RB. When lungs on mountains leak: studying pulmonary edema at high altitudes. $N$ Engl $J$ Med 1991; 325: 1036-1037.

2. Kawashima A, Kubo K, Kobayashi T, Sekiguchi M. Hemodynamic responses to acute hypoxia, hypobaria, and exercise in subjects susceptible to high altitude pulmonary edema. J Appl Physiol 1989; 67: 1982-1989.

3. Giaid A, Yanagisawa M, Langleben D, et al. Expression of endothelin in the lungs of patients with pulmonary hypertension. N Engl J Med 1993; 328: 1732-1739.

4. Goerre S, Wenk M, Bartsch P, et al. Endothelin-1 in pulmonary hypertension associated with high altitude exposure. Circulation 1995; 90: 359-364.

5. Barnes PJ. Endothelins and pulmonary diseases. J Appl Physiol 1994; 77: 1051-1059.

6. Albelda SM. Endothelial and epithelial cell adhesion molecules. Am J Respir Cell Mol Biol 1991; 4: 195-203.

7. Damme JV. Interleukin-8 and related chemotactic cytokines. In: Thomson A, ed. The Cytokine Handbook. San Diego, Academic Press, 1994; pp. 185-208.

8. Miller EJ, Cohen AB, Nagao S, et al. Elevated levels of
NAP-1/ interleukin- 8 are present in the airspace of patients with the adult respiratory distress syndrome and are associated with increased mortality. Am Rev Respir Dis 1992; 146: 427-432.

9. Donnelly SC, Strieter RM, Kunkel SL, et al. Interleukin8 and development of adult respiratory distress syndrome in atrisk patient groups. Lancet 1993; 341: 643-647.

10. Pilewski JM, Albelda SM. Adhesion molecules in the lung: an overview. Am Rev Respir Dis 1993; 148: S31-S37.

11. Ando K, Hirata Y, Shichiri M, Emori T, Marumo F. Presence of immunoreactive endothelin in human plasma. FEBS Lett 1989; 245: 164-166.

12. Shirakami G, Nakao K, Saito Y, et al. Acute pulmonary alveolar hypoxia increases lung and plasma endothelin-1 levels in conscious rats. Life Sci 1991; 48: 969-976.

13. Schoene RB, Swenson ER, Pizzo CJ, et al. The lung at altitude: bronchoalveolar lavage in acute mountain sickness and pulmonary edema. J Appl Physiol 1988; 64: 2605-2613.

14. Eldridge MW, Johnson DH, Grissom CK, Hill HR. Interleukin-6 and E-selectin blood levels in climbers following ascent to 4,400 meters. Am J Respir Crit Care Med 1995; 151: A69. 